\title{
Photo-Gated Intervalence Charge Transfer of Ethynylferrocene \\ Functionalized Titanium Dioxide Nanoparticles
}

Yi Peng, ${ }^{a}$ Jia En Lu,,${ }^{a}$ Christopher P. Deming, ${ }^{a}$ Limei Chen, ${ }^{a}$ Nan Wang, ${ }^{b}$ Eduardo Y. Hirata, ${ }^{\text {a }}$ and

\begin{abstract}
Shaowei Chen*,a
${ }^{a}$ Department of Chemistry and Biochemistry, University of California, 1156 High Street, Santa Cruz, California 96064, USA. *E-mail: shaowei@ucsc.edu

${ }^{b}$ New Energy Research Institute, School of Environment and Energy, South China University of Technology, Guangzhou Higher Education Mega Center, Guangzhou 510006, CHINA
\end{abstract}

\begin{abstract}
Ethynylferrocene-functionalized titanium dioxide nanoparticles $\left(\mathrm{TiO}_{2}-\mathrm{eFc}\right)$ were synthesized, for the first time ever, by a modified two-phase hydrothermal method. Transmission electron microscopic measurements showed that the nanoparticles were rather uniform in size, with an average diameter of $4.0 \pm 0.5 \mathrm{~nm}$ and well-defined lattice fringes that were consistent with those of anatase $\mathrm{TiO}_{2} .{ }^{1} \mathrm{H}$ NMR, FTIR and XPS measurements confirmed the attachment of the ferrocenyl ligands onto the nanoparticle surface, most likely forming $\mathrm{Ti}-\mathrm{C} \equiv \mathrm{C}-\mathrm{Fc}$ interfacial bonds. The resulting nanoparticles exhibited a bandgap of ca. $3.3 \mathrm{eV}$, and two emission bands in photoluminescence measurements at 351 and $460 \mathrm{~nm}$, with the former due to the $\mathrm{TiO}_{2}$ cores whereas the latter from intraparticle charge delocalization between the nanoparticle-bound acetylene moieties under UV photoirradiation. In electrochemical measurements, only one pair of voltammetric peaks were observed in the dark, due to the redox reactions of the nanoparticle-bound ferrocenyl
\end{abstract}


groups. However, when subject to photoirradiation with UV lights (254 and $365 \mathrm{~nm}$ ), two pairs of voltammetric peaks appeared, with a respective peak spacing of 174 and $198 \mathrm{mV}$, suggesting intervalence charge transfer (IVCT) between the ferrocenyl moieties bound on the nanoparticle surface. This arose from photo-enhanced electrical conductivity of the $\mathrm{TiO}_{2}$ cores that served as part of the chemical linkage bridging the ferrocenyl moieties. Significantly, such photo-gated IVCT varied with the photoexcitation energy that dictated the intraparticle charge transfer pathways.

Keywords: $\mathrm{TiO}_{2}$ nanoparticle; ferrocene; photoluminescence; intervalence charge transfer; charge transfer pathway

\section{Introduction}

Intervalence charge transfer (IVCT) refers to a unique process typically observed with organometallic complexes consisting of two or more chemically identical redoxactive metal centers that are bridged by conjugated chemical linkages, such as ferrocene oligomers and the Creutz-Taube ion [1,2]. At mixed valence, rapid metal-metal charge transfer (MMCT) occurs, which leads to the emergence of new optical and electrochemical properties [3-7]. Based on the degree of intramolecular charge delocalization, the mixed valence species are generally categorized as Class I, II or III compounds, as suggested by Robin and Day [8-10]. Recently, it has been found that IVCT may also be achieved with metal nanoparticles whereby functional moieties are bound onto the nanoparticle surface through conjugated metal-ligand interfacial bonds and the metallic nanoparticle cores act as conducting spacers to facilitate intraparticle 
charge delocalization [11-13]. Experimentally, a variety of conjugated metal-ligand interfacial bonds have recently been formed for nanoparticle surface functionalization. For instance, metal-carbene bonds $(\mathrm{M}=\mathrm{CH}-)$, metal-vinylidene bonds $(\mathrm{M}=\mathrm{C}=\mathrm{CH}-)$, metal-acetylide bonds $(\mathrm{M}-\mathrm{C} \equiv \mathrm{C}-)$, and metal-nitrene $(\mathrm{M}=\mathrm{N})$ bonds have been formed for the functionalization of a variety of transition-metal nanoparticles including ruthenium, platinum, gold and palladium [14-20].

One may notice that these prior studies are largely confined to metal nanoparticles by taking advantage of the strong affinity of transition metal surfaces to various organic functional moieties. An immediate question arises. Is it possible to extend the chemistry to semiconductor nanoparticles where the nanoparticle photoactivity may be exploited as a new, effective variable in the manipulation of intraparticle charge delocalization? Specifically, because of the apparent bandgap, the low electrical conductivity of semiconductor nanoparticles in the dark would diminish the electronic communication between the particle-bound functional moieties; whereas under photoirradiation with photon energy greater than the nanoparticle bandgap, the enhanced electrical conductivity is anticipated to facilitate intraparticle charge transfer. This photo-gating effects have indeed been observed in recent studies with semiconducting $\mathrm{Pt}_{10}$ nanoclusters [12] and silicon nanoparticles [21]. Yet, in these earlier studies [12, 21], the nanoparticle-mediated IVCT remained very weak even under photoirradiation, where the resulting nanoparticles behaved analogously to a Class I/II compound, as manifested in spectroscopic and electrochemical measurements. This is the primary motivation of the present study where we used ethynylferrocene functionalized titanium dioxide $\left(\mathrm{TiO}_{2}-\mathrm{eFc}\right)$ nanoparticles as the illustrating example to demonstrate that with a proper alignment of the photon energy and 
the nanoparticle bandgap energy, nanoparticle-mediated IVCT may be enhanced significantly.

Herein, stable $\mathrm{TiO}_{2}-\mathrm{eFc}$ nanoparticles were synthesized, for the first time ever, by a simple two-phase hydrothermal method using titanium(IV) $n$-propoxide as the titanium source and ethynylferrocene as the capping ligands. The resulting nanoparticles exhibited well-defined lattice fringes that were consistent with those of anatase $\mathrm{TiO}_{2}$, and an average diameter of $4.0 \pm 0.5 \mathrm{~nm}$, as manifested in transmission electron microscopic measurements. Spectroscopic measurements confirmed the successful attachment of the ligands onto the nanoparticle surface, most likely forming $\mathrm{Ti}-\mathrm{C} \equiv \mathrm{C}-\mathrm{Fc}$ interfacial bonds. Interestingly, electrochemical measurements in the dark exhibited only a single pair of voltammetric peaks, signifying the lack of electronic communication between the particle-bound ferrocenyl moieties. Yet under UV photoirradiation, apparent IVCT was observed, as evidenced by the emergence of two pairs of voltammetric peaks, and the nanoparticle-mediated IVCT was found to vary with the photoirradiation wavelength. This was likely due to a deliberate control of the intraparticle charge transfer pathway.

\section{Experimental Section}

2.1 Chemicals. Titanium(IV) n-propoxide (99\%, ACROS), tert-butylamine (99\%, ACROS), ethynylferrocene (eFc, 97\%, ACROS), 4-ethynylphenylacetylene (EPA, 97\%, ACROS), and ferrocenecarboxylic acid (FCA, 97\%, ACROS) were all used as received without any further purification. Tetra- $n$-butylammonium perchlorate (TBAP, 98\%, TCI America) was used after recrystallization 4 times in ethanol. Solvents were purchased at the highest purity available from typical commercial sources and also used as received. Water was deionized with a Barnstead Nanopure Water System $(18.3 \mathrm{M} \Omega \mathrm{cm})$. 
2.2 Synthesis of $\mathrm{TiO}_{2}-\mathrm{eFc}$ nanoparticles. $\mathrm{TiO}_{2}-\mathrm{eFc}$ nanoparticles were synthesized via a two-phase hydrothermal approach. Experimentally, $50 \mu \mathrm{L}$ of tert-butylamine was dissolved in $5 \mathrm{~mL}$ of water and the solution was transferred into a $20 \mathrm{~mL}$ Teflon-lined stainless-steel autoclave, into which was then added $4 \mathrm{~mL}$ of toluene. Separately, $75 \mathrm{mg}$ of titanium(IV) $n$-propoxide $(0.25 \mathrm{mmol})$ and $35 \mathrm{mg}(0.17 \mathrm{mmol})$ of eFc were dissolved in $1 \mathrm{~mL}$ of toluene, and then the mixture was added to the toluene layer in the autoclave gently without any stirring. The autoclave was sealed and heated up to $180{ }^{\circ} \mathrm{C}$ and kept at this temperature for $12 \mathrm{~h}$. After it was cooled down to room temperature, the toluene layer was collected and dried by rotatory evaporation. The obtained products were rinsed by pentane for five times to remove excess free ligands and other by-products. The purified products were denoted as $\mathrm{TiO}_{2}-\mathrm{eFc}$.

Two control samples were also prepared in the same fashion except that the capping ligand eFc was replaced by EPA or FCA. The resulting nanoparticles were denoted as $\mathrm{TiO}_{2}$-EPA and $\mathrm{TiO}_{2}$-FCA, respectively.

2.3 Characterization. The morphology and size of the organically capped $\mathrm{TiO}_{2}$ nanoparticles were characterized by transmission electron microscopic (TEM) studies (Philips CM300 at $300 \mathrm{kV}$ ). ${ }^{1} \mathrm{H}$ NMR spectroscopic measurements were carried out by using concentrated nanoparticle solutions in $\mathrm{CDCl}_{3}$ with a Varian Unity $500 \mathrm{MHz} \mathrm{NMR}$ spectrometer. FTIR measurements were carried out with a PerkinElmer FTIR spectrometer (Spectrum One, spectral resolution $4 \mathrm{~cm}^{-1}$ ), where the samples were prepared by casting the nanoparticle solution onto a ZnSe disk. X-ray photoelectron spectroscopic (XPS) measurement was carried out with a PHI 5400/XPS instrument equipped with an $\mathrm{Al} \mathrm{K}$ s source operated at $350 \mathrm{~W}$ and $10^{-9}$ Torr. UV-vis spectra were 
collected with a PerkinElmer Lambda 35 UV-vis spectrometer, and photoluminescence measurements were performed with a PTI fluorospectrometer.

2.4 Electrochemistry. Voltammetric measurements were carried out with a CHI 440 electrochemical workstation either in the dark, or under photoirradiation with a UV lamp (254 or $365 \mathrm{~nm}$ ). A polycrystalline gold disk electrode (sealed in glass tubing) was used as the working electrode, which was polished with alumina slurries of $0.05 \mu \mathrm{m}$ and then cleaned by sonication in $\mathrm{H}_{2} \mathrm{SO}_{4}$, and Nanopure water prior to data collection. $\mathrm{A} \mathrm{Ag} / \mathrm{AgCl}$ wire and a Pt coil were used as the (quasi)reference and counter electrodes, respectively. Prior to data collection, the electrolyte solution was deaerated by bubbling ultrahigh purity $\mathrm{N}_{2}$ for at least 20 min and blanketed with a nitrogen atmosphere during the entire experimental procedure.

\section{Results and Discussion}

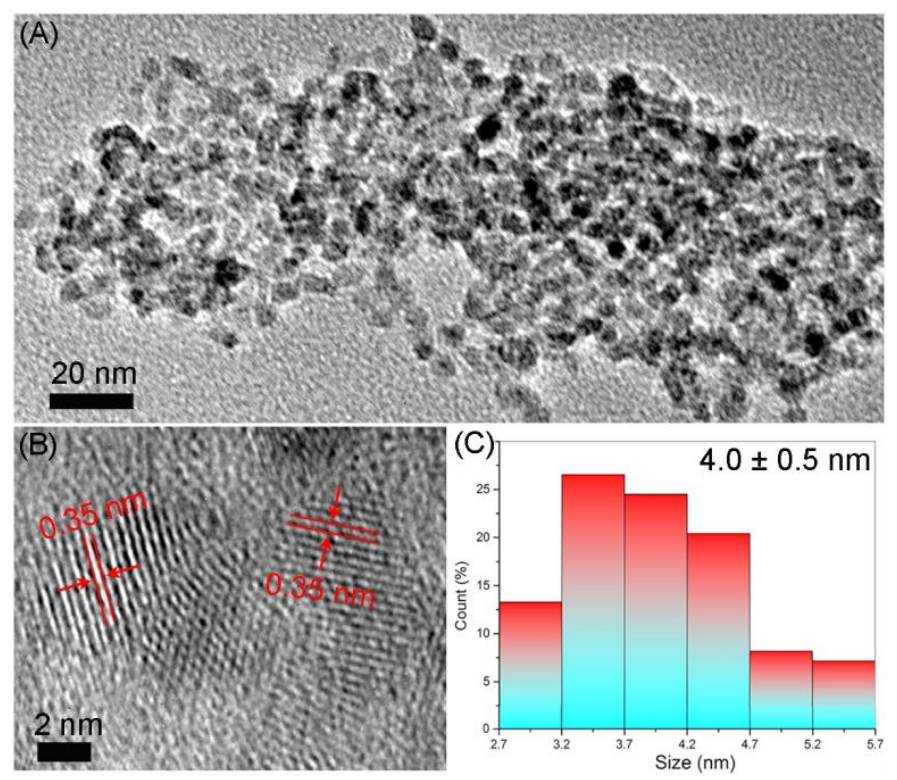

Figure 1. (A, B) Representative TEM images of $\mathrm{TiO}_{2}-\mathrm{eFc}$ nanoparticles. Scale bars are (A) $20 \mathrm{~nm}$ and (B) $2 \mathrm{~nm}$. (C) The corresponding nanoparticle core size histogram.

The morphology of the nanoparticles was firstly characterized by TEM measurements. Figure 1 (A) depicts a representative TEM image of the $\mathrm{TiO}_{2}-\mathrm{eFc}$ 
nanoparticles. One can see that the nanoparticles exhibited well-defined lattice fringes, where the lattice spacing of $0.35 \mathrm{~nm}$ is consistent with the interplanar distance of anatase $\mathrm{TiO}_{2}$ (101) crystalline planes (JCPDS 75-1537), as manifested in Figure 1 (B) [22]. In addition, statistical analysis based on more than 100 nanoparticles showed that the average diameter of the nanoparticles was estimated to be $4.0 \pm 0.5 \mathrm{~nm}$, as depicted in the core size histogram in Figure 1 (C). Consistent results were obtained with the $\mathrm{TiO}_{2}$-EPA (Figure S1) and $\mathrm{TiO}_{2}$-FCA (Figure S2) nanoparticles, except that the average core diameters were somewhat different at $4.4 \pm 0.6 \mathrm{~nm}$ and $10.9 \pm 2.8 \mathrm{~nm}$, respectively.

The successful incorporation of the eFc ligands onto the $\mathrm{TiO}_{2}$ nanoparticle surface was confirmed by ${ }^{1} \mathrm{H}$ NMR and FTIR spectroscopic measurements. Figure 2 (A) depicts the ${ }^{1} \mathrm{H}$ NMR spectrum of the $\mathrm{TiO}_{2}-\mathrm{eFc}$ nanoparticles in $\mathrm{CDCl}_{3}$, where two broad peaks centered around 4.2 and $3.5 \mathrm{ppm}$ can be found and assigned to the ferrocenyl protons of eFc (the peak at $2.35 \mathrm{ppm}$ likely arose from the methyl protons of residual toluene) [12, $23,24]$. The fact that no sharp features were observed, along with the absence of alkynyl $(\equiv \mathrm{C}-\mathrm{H})$ protons at $2.7 \mathrm{ppm}$, suggests that the nanoparticles were spectroscopically clean and free of monomeric eFc ligands [25]. The structures of the eFc capping ligands were further analyzed by FTIR measurements. From Figure 2 (B), one can see that whereas the terminal $\equiv \mathrm{C}-\mathrm{H}$ vibration can be clearly identified at $3292 \mathrm{~cm}^{-1}$ with the $\mathrm{eFc}$ monomers, it vanished altogether with the $\mathrm{TiO}_{2}-\mathrm{eFc}$ nanoparticles, suggesting effective cleavage of the $\equiv \mathrm{C}-\mathrm{H}$ bonds when the $\mathrm{eFc}$ ligands were bound onto the nanoparticle surface by hydrothermal treatment (inset to Figure 2 (A)). Additionally, the ferrocene ring $=\mathrm{C}-\mathrm{H}$ stretch and the $\mathrm{C} \equiv \mathrm{C}$ stretch can be identified at 3090 and $2108 \mathrm{~cm}^{-1}$ for $\mathrm{TiO}_{2}-\mathrm{eFc}$, both virtually invariant as compared to those observed with monomeric eFc [26]. This is in 
marked contrast with results in prior studies [11-13, 27], where the eFc ligands were bound onto metal nanoparticles and the ferrocenyl ring $=\mathrm{C}-\mathrm{H}$ and $\mathrm{C} \equiv \mathrm{C}$ stretches were found to exhibit an apparent red-shift, due to intraparticle charge delocalization among the particle-bound acetylene moieties as a result of the formation of conjugated metalligand interfacial bonds. The fact that no apparent red-shifts were observed in $\mathrm{TiO}_{2}-\mathrm{eFc}$ may be ascribed to the low electrical conductivity of the $\mathrm{TiO}_{2}$ cores that impeded intraparticle charge transfer.

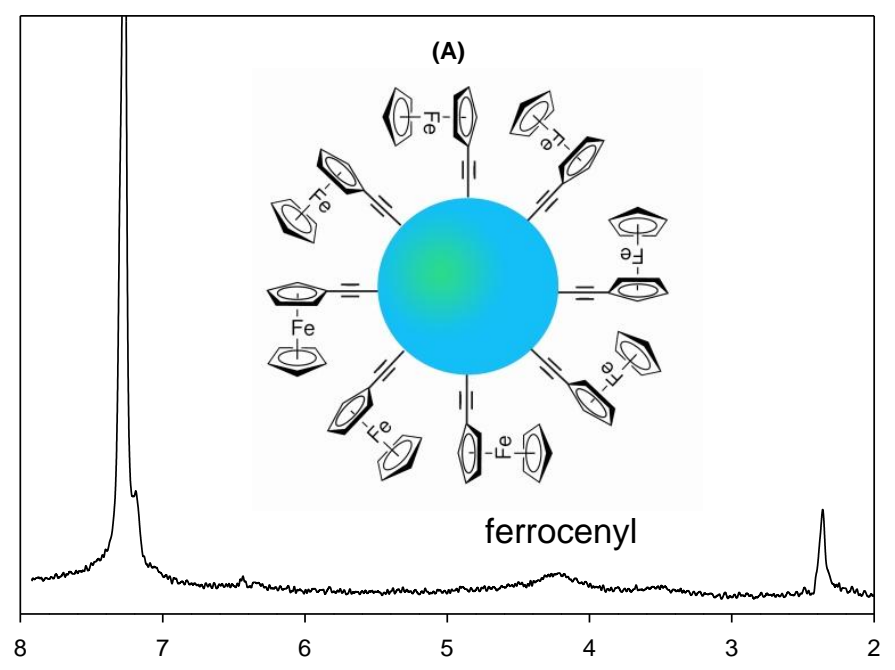

Chemical Shift/ppm

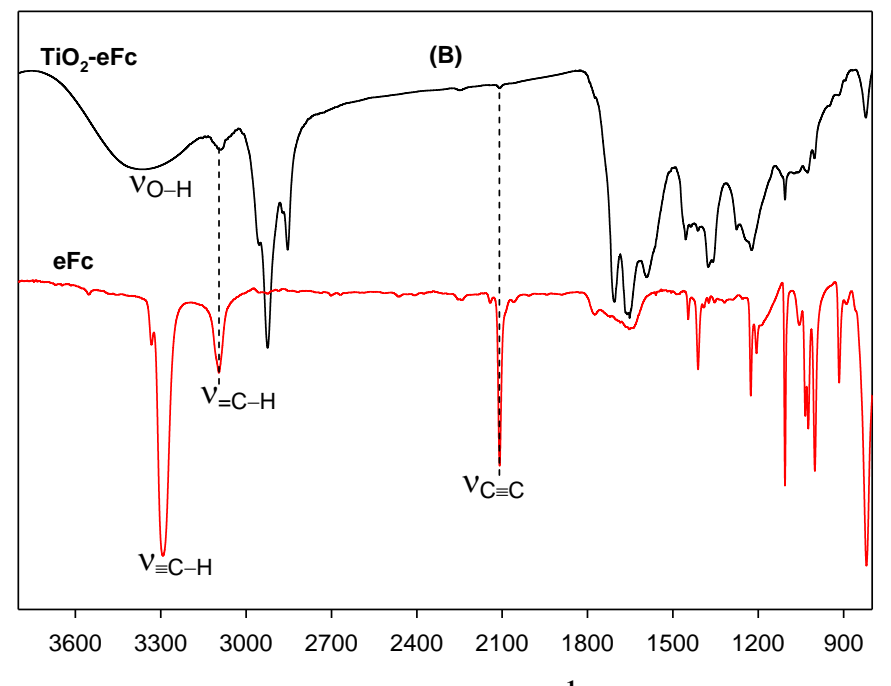

Wavenumber $/ \mathrm{cm}^{-1}$ 
Figure 2. (A) ${ }^{1} \mathrm{H}$ NMR spectrum of the $\mathrm{TiO}_{2}-\mathrm{eFc}$ nanoparticles in $\mathrm{CDCl}_{3}$. Inset is the schematic structure of $\mathrm{TiO}_{2}-\mathrm{eFc}$ nanoparticles. (B) FTIR spectra of the eFc monomer (black curve) and the $\mathrm{TiO}_{2}-\mathrm{eFc}$ nanoparticles (red curve).

The elemental composition and valence state of the $\mathrm{TiO}_{2}-\mathrm{eFc}$ nanoparticles was further characterized by XPS measurements. From the survey spectrum in the inset to Figure 3 (A), the $\mathrm{C} 1 \mathrm{~s}, \mathrm{Ti} 2 \mathrm{p}, \mathrm{O} 1 \mathrm{~s}$, and $\mathrm{Fe} 2 \mathrm{p}$ electrons can be readily identified at approximately 284, 459, 530 and $710 \mathrm{eV}$, respectively. Figure 3 (A) depicts the highresolution scan of the Ti2p electrons, where deconvolution yields two subpeaks at 458.5 $\mathrm{eV}\left(\mathrm{Ti} 2 \mathrm{p}_{3 / 2}\right)$ and $464.2 \mathrm{eV}\left(\mathrm{Ti} 2 \mathrm{p}_{1 / 2}\right)$. The binding energy spacing of $5.7 \mathrm{eV}$ is consistent with the spin-orbit coupling of the $\mathrm{Ti} 2 \mathrm{p}$ electrons in $\mathrm{TiO}_{2}$ [28]. For the $\mathrm{Fe} 2 \mathrm{p}$ electrons in Figure 3 (B), a doublet can be resolved at $709.8 \mathrm{eV}\left(\mathrm{Fe} 2 \mathrm{p}_{3 / 2}\right)$ and $722.8 \mathrm{eV}\left(\mathrm{Fe} 2 \mathrm{p}_{1 / 2}\right)$, along with a satellite peak at $713.7 \mathrm{eV}$, consistent with those of ferrocene derivatives [29]. Figure 3 (C) displays the $\mathrm{C} 1 \mathrm{~s}$ spectrum, where the major peak centered at $284.8 \mathrm{eV}$ can be assigned to the ferrocenyl carbons [30], while the small peak centered at $284.3 \mathrm{eV}$ likely arose from carbons in $\mathrm{Ti}-\mathrm{C} \equiv \mathrm{C}-\mathrm{Fc}$ bonds. Note that this binding energy is actually very close to that of $\mathrm{C}=\mathrm{C}$ bonds observed with graphene or carbon nanotubes (ca. 284.4 eV) [31-33], but markedly higher than that of $\mathrm{C} \equiv \mathrm{C}$ (ca. $283.5 \mathrm{eV}$ ) [34, 35]. This is consistent with the formation of $\mathrm{Ti}-\mathrm{C} \equiv \mathrm{C}-\mathrm{Fc}$ interfacial bonds which likely involved back donation of $\mathrm{Ti} 3 \mathrm{~d}$ electrons to the carbon $\pi *$ orbital [36], leading to a decrease of the effective bond order [11]. The O1s spectrum is shown in Figure 3 (D), where deconvolution yields two peaks at 530.0 and $531.7 \mathrm{eV}$. The former is consistent with oxygen in $\mathrm{Ti}-\mathrm{O}-\mathrm{Ti}$ in $\mathrm{TiO}_{2}$, whereas the latter is likely from hydroxyl species on the $\mathrm{TiO}_{2}$ surface $(\mathrm{Ti}-\mathrm{O}-\mathrm{H})$ [37]. The presence of $\mathrm{Ti}-\mathrm{O}-\mathrm{H}$ bonds is consistent with the FTIR measurement where the $\mathrm{O}-\mathrm{H}$ vibrational stretch can be seen at $3370 \mathrm{~cm}^{-1}$ (Figure 2 (B)). 
Taken together, these results confirmed that the $\mathrm{TiO}_{2}$ nanoparticle surface was indeed functionalized by ethynylferrocene ligands most likely forming $\mathrm{Ti}-\mathrm{C} \equiv \mathrm{C}-\mathrm{Fc}$ interfacial bonds (inset to Figure 2 (A)). Furthermore, based on the integrated peak areas of the Fe2p and Ti2p electrons, the atomic ratio of Fe:Ti was estimated to be 0.096:1. Given that the nanoparticle core diameter is $4.0 \mathrm{~nm}$ (Figure 1) and the density of bulk $\mathrm{TiO}_{2}$ is $4.23 \mathrm{~g}$ $\mathrm{cm}^{-3}$, one can therefore estimate the footprint of one eFc ligand on the nanoparticle surface to be $0.48 \mathrm{~nm}^{2}$, which is slightly larger than the cross-sectional area of the ferrocenyl moiety $\left(0.45 \mathrm{~nm}^{2}\right)$ [38].
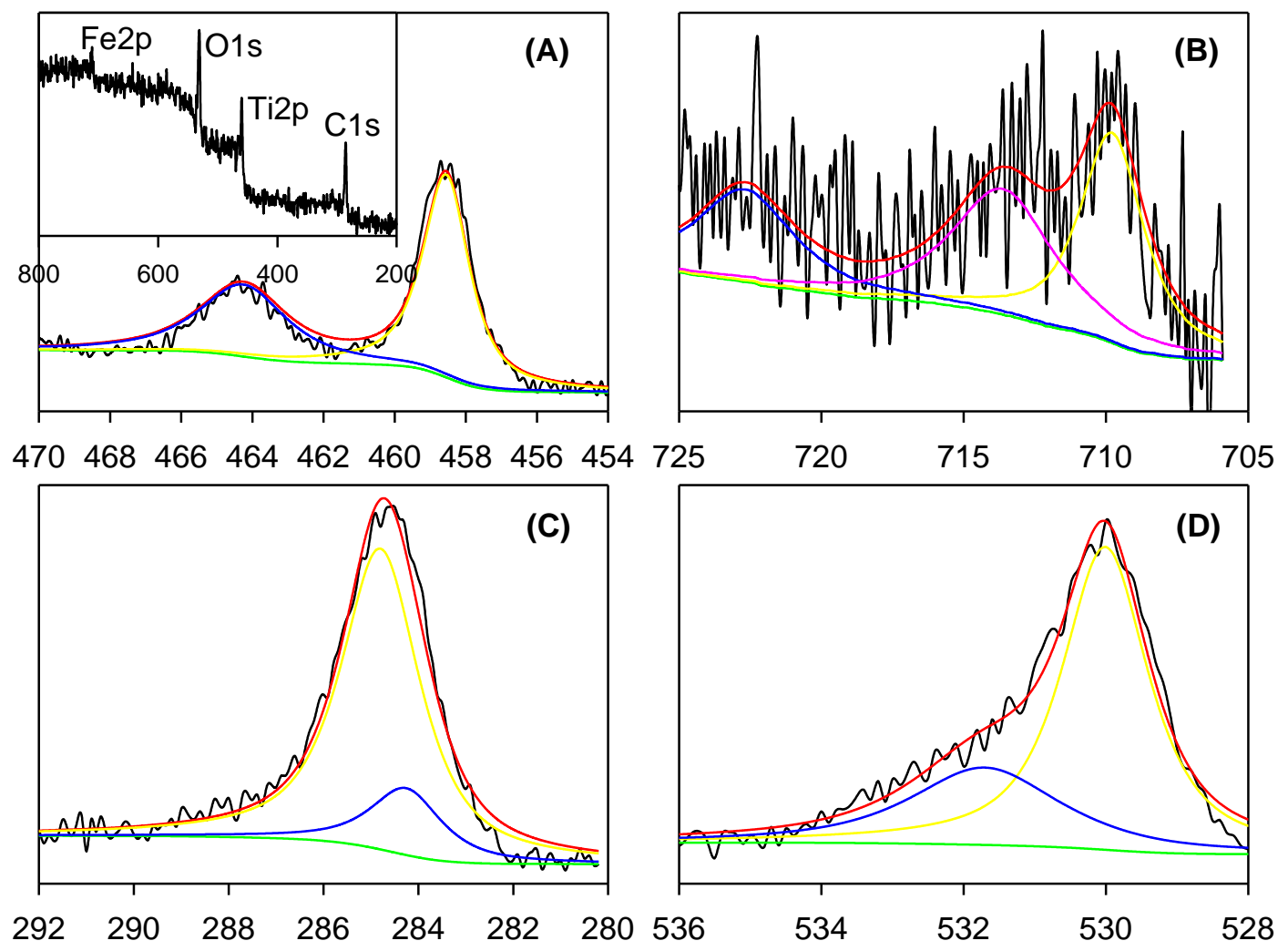

Binding Energy/eV

Figure 3. High-revolution XPS spectra of $\mathrm{TiO}_{2}-\mathrm{eFc}$ nanoparticles: (A) Ti $2 p,(B) \mathrm{Fe} 2 p$, (C) $\mathrm{C} 1 \mathrm{~s}$, and (D) $O$ 1s electrons. Black curves are experimental data, and colored curves are deconvolution fits. Inset to panel (A) is the XPS survey spectrum of the $\mathrm{TiO}_{2}-\mathrm{eFc}$ nanoparticles. 
UV-vis and photoluminescence measurements were then performed to study the optical properties of the $\mathrm{TiO}_{2}-\mathrm{eFc}$ nanoparticles. Note that $\mathrm{TiO}_{2}$ is an indirect-bandgap semiconductor, and the bandgap between the conduction band and valence band can be estimated from UV-vis measurements. As shown in Figure 4 inset, when $(\alpha h v)^{1 / 2}$ is plotted against (hv $-\mathrm{E}_{\mathrm{g}}$ ), with $\alpha$ being the optical absorbance and $\mathrm{h} v$ being the photon energy, extrapolation of the spectrum to the $x$ axis (red dashed line) may be exploited for the quantitative assessment of the nanoparticles bandgap [39], which is about $3.3 \mathrm{eV}$ (the results were almost identical for the $\mathrm{TiO}_{2}$-EPA and $\mathrm{TiO}_{2}$-FCA nanoparticles, insets to Figure S3), very close to that reported for anatase $\mathrm{TiO}_{2}[40,41]$. Consistent results were obtained in photoluminescence measurements (Figure 4). One can see that the $\mathrm{TiO}_{2}-\mathrm{eFc}$ nanoparticles exhibited two well-defined emission peaks at $351 \mathrm{~nm}(3.53 \mathrm{eV})$ and $459 \mathrm{~nm}$ $(2.70 \mathrm{eV})$ when excited at $288 \mathrm{~nm}(4.3 \mathrm{eV})$; and at a lower excitation energy $(362 \mathrm{~nm}$, $3.43 \mathrm{eV}$ ), only the $459 \mathrm{~nm}$ emission was observed but with much stronger intensity. In contrast, for the $\mathrm{TiO}_{2}-\mathrm{FCA}$ nanoparticles where the carboxylate ligands were bound onto the oxide particle surface in a (nonconjugated) $\mathrm{Ti}-\mathrm{O}$ bidentate fashion [42], only a single emission peak was observed at $382 \mathrm{~nm}$ when excited at $312 \mathrm{~nm}$ (Figure S3). This suggests that the emission at $351 \mathrm{~nm}$ observed above with the $\mathrm{TiO}_{2}-\mathrm{eFc}$ nanoparticles was likely due to the $\mathrm{TiO}_{2}$ cores [43], whereas the $459 \mathrm{~nm}$ emission is actually very similar to what we have observed with alkyne-functionalized metal nanoparticles, where the photoluminescence was ascribed to intraparticle charge delocalization as a results of the conjugated $\mathrm{M}-\mathrm{C} \equiv$ interfacial bonding interactions, such that the particle-bound acetylene $(C \equiv C)$ moieties behaved analogously to diacetylene $(C \equiv C-C \equiv C)$ derivatives $[15,17,44]$. In the present study with $\mathrm{TiO}_{2}-\mathrm{eFc}$ nanoparticles, it is likely that such intraparticle charge 
delocalization occurred when the nanoparticles were exposed to UV photoirradiation leading to enhanced electrical conductivity of the $\mathrm{TiO}_{2}$ nanoparticles. In fact, for $\mathrm{TiO}_{2}$ nanoparticles capped with ethylphenylacetylene $\left(\mathrm{TiO}_{2}-\mathrm{EPA}\right)$, two emission peaks were also observed at $360 \mathrm{~nm}$ and $425 \mathrm{~nm}$ by photoexcitation at $295 \mathrm{~nm}$, and only one emission peak centered at $425 \mathrm{~nm}$ by excitation at a shorter wavelength of $355 \mathrm{~nm}$ (Figure S3). These observations are very similar to those observed above with $\mathrm{TiO}_{2}$-eFc. Taken together, these results suggest that the emission at the higher energy might be ascribed to the $\mathrm{TiO}_{2}$ cores, whereas the one at lower energy to the acetylene moieties that were bound onto the $\mathrm{TiO}_{2}$ surface.

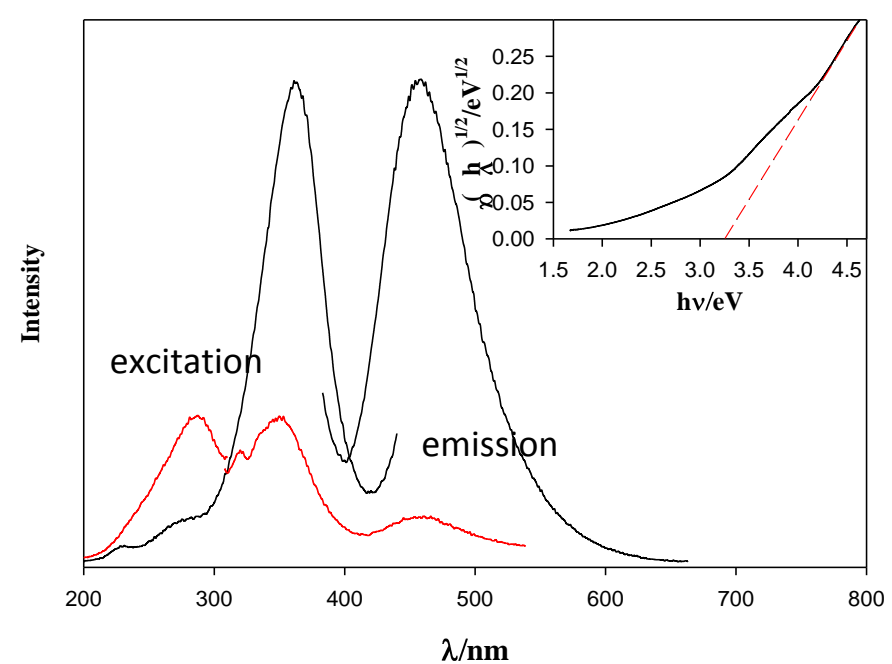

Figure 4. Excitation and emission spectra of $\mathrm{TiO}_{2}-\mathrm{eFc}$ nanoparticle in $\mathrm{CHCl}_{3}$. Inset is the corresponding UV/Vis spectrum, where $\alpha$ is the absorbance and $h v$ is the photon energy. Red dashed line represents linear extrapolation to the $x$ axis.

Voltammertric measurements were then carried out to further examine the chargetransfer properties of the $\mathrm{TiO}_{2}-\mathrm{eFc}$ nanoparticles. Figure 5 depicts the square-wave voltammograms (SWVs) of the $\mathrm{TiO}_{2}-\mathrm{eFc}$ nanoparticles under different experimental conditions at a concentration of $2 \mathrm{mg} \mathrm{mL}^{-1}$ in $\mathrm{CHCl}_{3}$ with $0.1 \mathrm{~mol} \mathrm{~L}^{-1} \mathrm{TBAP}$ as the supporting electrolyte. When the voltammograms were acquired in the dark (Figure 5 (A), 
solid curve), a single pair of voltammetric peaks can be clearly seen standing out of the featureless background (dashed curve), with the formal potential $\mathrm{E}^{\circ}=+122 \mathrm{mV}$ (vs. $\mathrm{Fc}^{+} / \mathrm{Fc}$ ), which is attributable to the redox reaction of the ferrocene moieties bound on the $\mathrm{TiO}_{2}$ nanoparticle, and the small peak splitting $\left(\Delta \mathrm{E}_{\mathrm{p}}=32 \mathrm{mV}\right)$ is consistent with the facile electron transfer kinetics of ferrocene. One may notice that despite the formation of the $\mathrm{Ti}-\mathrm{C} \equiv \mathrm{C}-\mathrm{Fc}$ bonds at the nanoparticle-ligand interface, no apparent IVCT was observed, which might be ascribed to the low electrical conductivity of the $\mathrm{TiO}_{2}$ core that limited the intraparticle charge transfer because of the substantial bandgap (Figure 4). This is analogous to results of our previous studies with carbon or silicon nanoparticles cores [21, 45], and in contrast with those obtained with metal nanoparticle cores [12, 13, 29]. That is, the voltammetric results in Figure 5 (A) suggest that $\mathrm{TiO}_{2}-\mathrm{eFc}$ nanoparticles in the dark behaved as a Class I compound, according to Robin and Day's classifications [8-10]. Interestingly, as exhibited in Figure 5 (B), when exposed to $254 \mathrm{~nm}$ UV irradiation, the results are markedly different from the performance in the dark, where two pairs of voltammetric peaks can be found and resolved by deconvolution at $\mathrm{E}^{\circ}=-10 \mathrm{mV}$ and $+164 \mathrm{mV}$ with a small peak splitting of $\Delta \mathrm{E}_{\mathrm{p}}=0$ and $12 \mathrm{mV}$. The peak potential spacing of $\Delta \mathrm{E}^{\circ}=+174 \mathrm{mV}$ suggested that the $\mathrm{TiO}_{2}-\mathrm{eFc}$ nanoparticles now became analogous to a Class II compound [8-10]. Similarly, under 365 nm UV photoirradiation (Figure 5 (C)), two pairs of voltammetric peaks can be obtained and resolved by deconvolution at $\mathrm{E}^{\circ}=$ $-28 \mathrm{mV}$ and $+170 \mathrm{mV}$, again, with a small peak splitting of $\Delta \mathrm{E}_{\mathrm{p}}=4 \mathrm{mV}$ and $16 \mathrm{mV}$. The fact that the peak potential spacing of $\Delta \mathrm{E}^{\circ}$ increased to $198 \mathrm{mV}$ indicated enhanced IVCT. Taken together, these results suggest effective nanoparticle-mediated IVCT when the nanoparticles were under UV photoirradiation (254 nm and $365 \mathrm{~nm}$ ), most likely 
because of enhanced electrical conductivity of the $\mathrm{TiO}_{2}$ cores under UV photoirradiation and the $\mathrm{Ti}-\mathrm{C} \equiv \mathrm{C}-\mathrm{Fc}$ conjugated interfacial bonds, in sharp contrast with results obtained in the dark. In fact, the large peak potential spacings $\left(\Delta \mathrm{E}^{\circ}\right)$ of $174 \mathrm{mV}(254 \mathrm{~nm}$ photoirradiation) and $198 \mathrm{mV}$ (365 $\mathrm{nm}$ photoirradiation) are actually comparable to that observed previously where the ferrocene moieties were bound onto ruthenium nanoparticles by ruthenium-carbene $(\mathrm{Ru}=\mathrm{C}) \pi$ bonds (ca. $200 \mathrm{mV}, \mathrm{Ru}=\mathrm{CH}-\mathrm{Fc}$ ) [13], but somewhat smaller than that $(265 \mathrm{mV})$ of ethynylferrocene-functionalized ruthenium nanoparticle involving $\mathrm{Ru}-\mathrm{C} \equiv \mathrm{C}-\mathrm{Fc}$ interfacial bonds [27].

In our previous study where ethynylferrocene was used to functionalize silicon ( $\mathrm{Si}$ $\mathrm{eFc}$ ) nanoparticle forming a $\mathrm{Si}-\mathrm{CH}=\mathrm{CH}-\mathrm{Fc}$ interfacial bond, photo-induced intervalence charge transfer was also observed but the peak potential spacing was markedly smaller at only $125 \mathrm{mV}$ [21]. This discrepancy may be attributed to the stronger conjugation of the $-\mathrm{C} \equiv \mathrm{C}-$ linkage in $\mathrm{TiO}_{2}-\mathrm{eFc}$ than $-\mathrm{CH}=\mathrm{CH}-$ in $\mathrm{Si}-\mathrm{eFc}$, and hence stronger intraparticle charge delocalization in the former. In contrast, when ferrocenecarboxylic acid was used as the surface capping ligand, no conjugated core-ligand interfacial bonds were formed, such that only one pair of voltammetric peaks were observed with $\mathrm{TiO}_{2}-\mathrm{FCA}$ either in the dark or under UV photoirradiations (Figure S4). This further confirmed the importance of the conjugated bridges for nanoparticle-mediated IVCT. In the present study, the photogated IVCT of $\mathrm{TiO}_{2}-\mathrm{eFc}$ nanoparticles was also analogous to electronic coupling observed in organometallic complexes where two terminal ferrocene moieties are connected by a bis-ethynyl/butadiynyl diruthenium bridge, such as $\mathrm{Fc}-(\mathrm{C} \equiv \mathrm{C})_{\mathrm{n}}-\mathrm{Ru}_{2}-(\mathrm{C} \equiv \mathrm{C})_{\mathrm{m}}-\mathrm{Fc}$ where $\mathrm{n}$ and $\mathrm{m}$ are 1 or $2[46]$. 


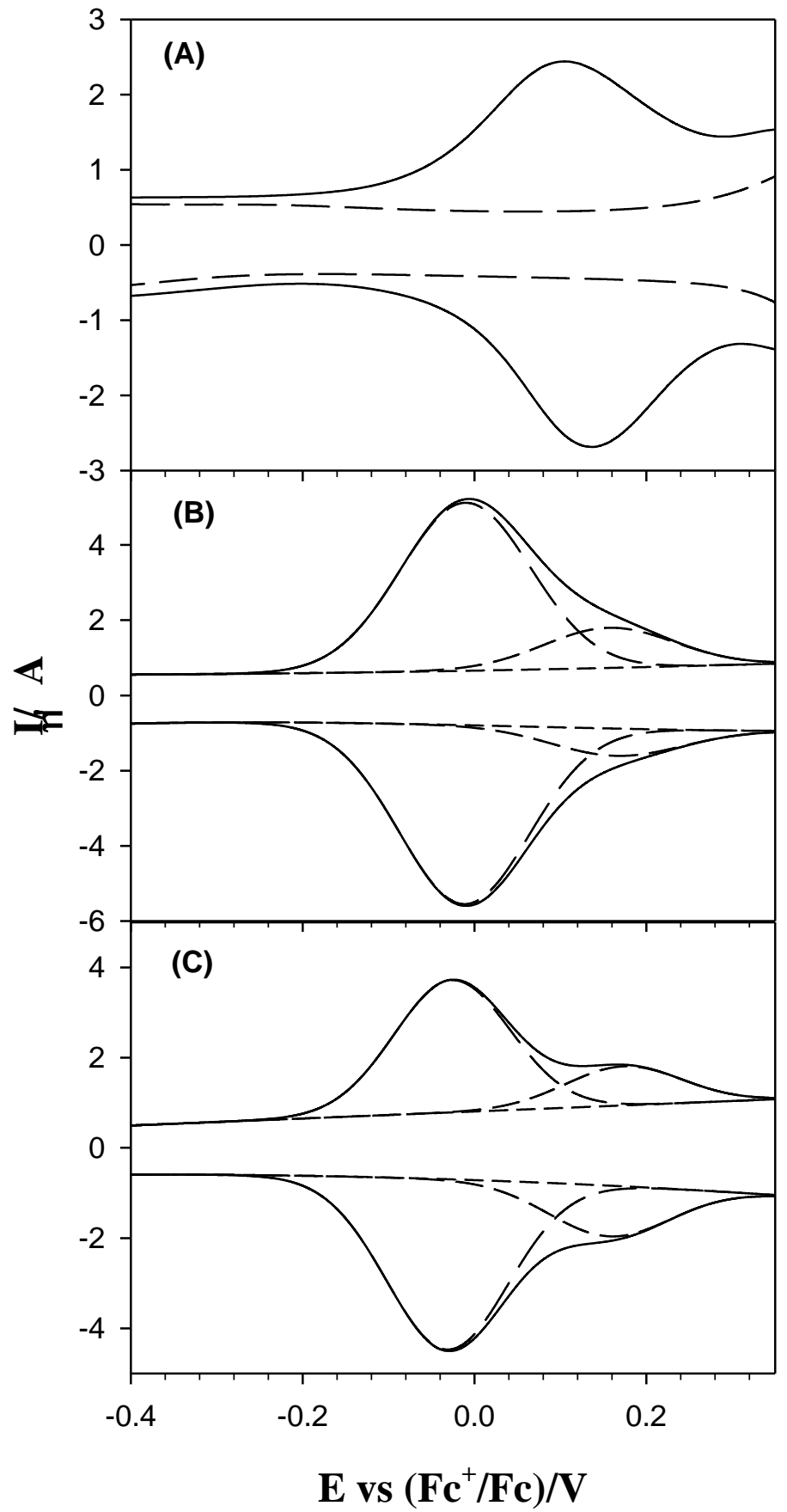

Figure 5. SWVs of $\mathrm{TiO}_{2}-\mathrm{eFc}$ nanoparticle $\left(2 \mathrm{mg} \mathrm{mL}^{-1}\right)$ at a gold electrode in $\mathrm{CHCl}_{3}$ containing 0.1 mol L $\mathrm{L}^{-1}$ TBAP recorded at different conditions: (A) in the dark; (B) under $254 \mathrm{~nm}$ UV photoirradiation, and (C) under $365 \mathrm{~nm}$ UV photoirradiation. In SWV measurements, increment of potential $2 \mathrm{mV}$, amplitude $25 \mathrm{mV}$, and frequency $15 \mathrm{~Hz}$. In panels $(\mathrm{B})$ and $(\mathrm{C})$, solid curves are experimental data and dashed curves are deconvolution fits. 
Furthermore, one may notice that the peak potential spacing $\left(\Delta \mathrm{E}^{\circ}\right)$ of $\mathrm{TiO}_{2}-\mathrm{eFc}$ nanoparticles under $365 \mathrm{~nm}$ photoirradiation is $20 \mathrm{mV}$ greater than that under $254 \mathrm{~nm}$ photoirradiation, although the photon energy of the former is lower. This may be accounted for by the variation of intraparticle charge transfer dynamics. As manifested in Figure 4, the emission of nanoparticle photoluminescence was markedly more intense by the excitation at $365 \mathrm{~nm}$ than at $254 \mathrm{~nm}$. In the former (365 nm excitation), the electrontransfer pathway primarily involved the particle-bound acetylene moieties, whereas in the latter (254 $\mathrm{nm}$ excitation), the $\mathrm{TiO}_{2}$ band-edge transition became the predominant route. This suggests that a proper alignment of the photon energy and the $\mathrm{TiO}_{2}$ electronic energy structure is critical in maximizing intraparticle charge delocalization.

\section{Conclusion}

In summary, ethynylerrocene-protected $\mathrm{TiO}_{2}$ nanoparticles were synthesized, for the first time ever, using a simple two-phase hydrothermal method. ${ }^{1} \mathrm{H}$ NMR, FTIR and XPS measurements suggested the formation of $\mathrm{Ti}-\mathrm{C} \equiv \mathrm{C}-\mathrm{Fc}$ interfacial bonds, and optical measurements exhibited two photoluminescence emission peaks at $351 \mathrm{~nm}$ and $459 \mathrm{~nm}$, with the former from the $\mathrm{TiO}_{2}$ cores and the latter from intraparticle charge delocalization between the nanoparticle-bound acetylene moieties. Electrochemically, only one pair of voltammetric peaks were observed in the dark, indicating the lack of electronic communication between the particle-bound ferrocenyl groups because of low electrical conductivity of the $\mathrm{TiO}_{2}$ cores. Yet, under UV photoirradiation, apparent IVCT was observed, as manifested by the emergence of two pairs of voltammetric peaks, with the peak potential spacing of $174 \mathrm{mV}$ under $254 \mathrm{~nm}$ photoirradiation and $198 \mathrm{mV}$ under 365 $\mathrm{nm}$ photoirradiation, consistent with behaviors of Class II compounds. In addition, the 
variation of the peak potential spacing with photoirradiation wavelength indicated the significance of the alignment of photoexcitation energy with nanoparticle electronic energy structures in determining the charge transfer dynamics (pathways) within the semiconductor nanoparticles and hence the manipulation of nanoparticle-mediated IVCT, a new variable that is unseen with metal nanoparticles.

\section{Acknowledgments}

This work was supported in part by the National Science Foundation (CHE-1265635 and DMR-1409396). TEM and XPS work was carried out at the National Center for Electron Microscopy and Molecular Foundry at the Lawrence Berkeley National Laboratory, which is supported by the US Department of Energy, as part of a user project.

Supplementary Data: TEM, UV-vis, photoluminescence, and voltammetric data of $\mathrm{TiO}_{2}$-EPA and $\mathrm{TiO}_{2}$-FCA nanoparticles.

\section{References}

[1] C. Creutz, H. Taube. Binuclear complexes of ruthenium ammines, J. Am. Chem. Soc. 95 (1973) 1086-1094.

[2] M.J. Powers, T.J. Meyer. Intervalence transfer in mixed-valence biferrocene ions, J. Am. Chem. Soc. 100 (1978) 4393-4398.

[3] O.S. Wenger. Photoswitchable mixed valence, Chem. Soc. Rev. 41 (2012) 3772-3779.

[4] W. Kaim, G.K. Lahiri. Unconventional mixed-valent complexes of ruthenium and osmium, Angew. Chem. Int. Ed. 46 (2007) 1778-1796.

[5] J. Hankache, O.S. Wenger. Organic mixed valence, Chem. Rev. 111 (2011) 5138-5178. 
[6] D.M. D'Alessandro, F.R. Keene. Intervalence charge transfer (IVCT) in trinuclear and tetranuclear complexes of iron, ruthenium, and osmium, Chem. Rev. 106 (2006) 22702298.

[7] P. Aguirre-Etcheverry, D. O'Hare. Electronic communication through unsaturated hydrocarbon bridges in homobimetallic organometallic complexes, Chem. Rev. 110 (2010) 4839-4864.

[8] M.B. Robin, P. Day. Mixed valence chemistry. A survey and classification, Adv. Inorg. Chem. Radiochem. 10 (1968) 247-422.

[9] S.F. Nelsen. \&quot;Almost delocalized\&quot; intervalence compounds, Chem. Eur. J 6 (2000) 581-588.

[10] K.D. Demadis, C.M. Hartshorn, T.J. Meyer. The localized-to-delocalized transition in mixed-valence chemistry, Chem. Rev. 101 (2001) 2655-2685.

[11] X. Kang, N.B. Zuckerman, J.P. Konopelski, S. Chen. Alkyne-stabilized ruthenium nanoparticles: Manipulation of intraparticle charge delocalization by nanoparticle charge states, Angew. Chem. 122 (2010) 9686-9689.

[12] P. Hu, L. Chen, C.P. Deming, X. Kang, S. Chen. Nanoparticle-mediated intervalence charge transfer: Core-size effects, Angew. Chem. 128 (2016) 1477-1481.

[13] W. Chen, S. Chen, F. Ding, H. Wang, L.E. Brown, J.P. Konopelski. Nanoparticle-mediated intervalence transfer, J. Am. Chem. Soc. 130 (2008) 12156-12162.

[14] K. Liu, X. Kang, Z.-Y. Zhou, Y. Song, L.J. Lee, D. Tian, S. Chen. Platinum nanoparticles functionalized with acetylene derivatives: Electronic conductivity and electrocatalytic activity in oxygen reduction, J. Electroanal. Chem. 688 (2013) 143-150. 
[15] X. Kang, N.B. Zuckerman, J.P. Konopelski, S. Chen. Alkyne-functionalized ruthenium nanoparticles: Ruthenium-vinylidene bonds at the metal-ligand interface, J. Am. Chem. Soc. 134 (2012) 1412-1415.

[16] X. Kang, Y. Song, S. Chen. Nitrene-functionalized ruthenium nanoparticles J. Mater. Chem. 22 (2012) 19250-19257.

[17] X. Kang, W. Chen, N.B. Zuckerman, J.P. Konopelski, S. Chen. Intraparticle charge delocalization of carbene-functionalized ruthenium nanoparticles manipulated by selective ion binding, Langmuir 27 (2011) 12636-12641.

[18] P. Hu, P.N. Duchesne, Y. Song, P. Zhang, S. Chen. Self-assembly and chemical reactivity of alkenes on platinum nanoparticles, Langmuir 31 (2015) 522-528.

[19] G. He, Y. Song, X. Kang, S. Chen. Alkyne-functionalized palladium nanoparticles: Synthesis, characterization, and electrocatalytic activity in ethylene glycol oxidation, Electrochim. Acta 94 (2013) 98-103.

[20] W. Chen, J.R. Davies, D. Ghosh, M.C. Tong, a. Joseph P Konopelski, S. Chen. Carbenefunctionalized ruthenium nanoparticles, Chem. Mater. 18 (2006) 5253-5259.

[21] Y. Peng, C.P. Deming, S. Chen. Intervalence charge transfer mediated by silicon nanoparticles, ChemElectroChem DOI: 10.1002/celc.201600114 (2016) n/a-n/a.

[22] K. Liu, Y. Song, S. Chen. Defective $\mathrm{TiO}_{2}$-supported $\mathrm{Cu}$ nanoparticles as efficient and stable electrocatalysts for oxygen reduction in alkaline media, Nanoscale 7 (2014) 1224-1232.

[23] L. Chen, P. Hu, C.P. Deming, W. Li, L. Li, S. Chen. Chemical reactivity of naphthalenecarboxylate-protected ruthenium nanoparticles: Intraparticle charge delocalization derived from interfacial decarboxylation, J. Phys. Chem. C 119 (2015) 15449-15454. 
[24] V.C. Gibson, N.J. Long, P.J. Oxford, A.J.P. White, D.J. Williams. Ferrocene-substituted bis(imino)pyridine iron and cobalt complexes: Toward redox-active catalysts for the polymerization of ethylene, Organometallics 25 (2006) 1932-1939.

[25] H.E. Gottlieb, V. Kotlyar, A. Nudelman. NMR chemical shifts of common laboratory solvents as trace impurities., J. Org. Chem. 62 (1997) 7512-7515.

[26] T. Cuenca, R. Gomez, P. Gomezsal, G.M. Rodriguez, P. Royo. Reactions of titanium(III) and zirconium(Iii) complexes with unsaturated organic-systems - X-ray structure of ([(eta5-C5h5)Zr(Ch3)]2[Mu-Eta-1-Eta-2-Cn(Me2c6h3)](Mu-Eta-5-Eta-5-C10h8)),

Organometallics 11 (1992) 1229-1234.

[27] W. Chen, N.B. Zuckerman, X. Kang, D. Ghosh, J.P. Konopelski, S. Chen. Alkyne-protected ruthenium nanoparticles, J. Phys. Chem. C 114 (2010) 18146-18152.

[28] X.B. Chen, L. Liu, P.Y. Yu, S.S. Mao. Increasing solar absorption for photocatalysis with black hydrogenated titanium dioxide nanocrystals, Science 331 (2011) 746-750.

[29] L. Chen, Y. Song, P. Hu, C.P. Deming, Y. Guo, S. Chen. Interfacial reactivity of ruthenium nanoparticles protected by ferrocenecarboxylates, Phys. Chem. Chem. Phys. 16 (2014) $18736-18742$.

[30] L.P.M. De Leo, E. de la Llave, D. Scherlis, F.J. Williams. Molecular and electronic structure of electroactive self-assembled monolayers, J. Chem. Phys. 138 (2013) 114707.

[31] C.K. Chua, Z. Sofer, P. Šimek, O. Jankovský, K. Klímová, S. Bakardjieva, Š. Hrdličková Kučková, M. Pumera. Synthesis of strongly fluorescent graphene quantum dots by cageopening buckminsterfullerene., ACS Nano 9 (2015) 2548-2555.

[32] T. Bordjiba, M. Mohamedi, L.H. Dao. New class of carbon-nanotube aerogel electrodes for electrochemical power sources, Adv. Mater. 20 (2008) 815-819. 
[33] S. Bae, H. Kim, Y. Lee, X. Xu, J.-S. Park, Y. Zheng, J. Balakrishnan, T. Lei, H.R. Kim, Y.I. Song, Y.-J. Kim, K.S. Kim, B. Ozyilmaz, J.-H. Ahn, B.H. Hong, S. Iijima. Roll-to-roll production of 30-inch graphene films for transparent electrodes., Nat. Nanotechnol. 5 (2010) 574-578.

[34] M. Rybachuk, J.M. Bell. Electronic states of trans-polyacetylene, poly(p-phenylene vinylene) and sp-hybridised carbon species in amorphous hydrogenated carbon probed by resonant Raman scattering, Carbon 47 (2009) 2481-2490.

[35] A. Hu, M. Rybachuk, Q.B. Lu, W.W. Duley. Direct synthesis of sp-bonded carbon chains on graphite surface by femtosecond laser irradiation, Appl. Phys. Lett. 91 (2007) 131906.

[36] G.V. Oshovsky, B. Hessen, J.N.H. Reek, B. de Bruin. Electronic selectivity tuning in titanium(III)-catalyzed acetylene cross-dimerization reactions, Organometallics 30 (2011) 6067-6070.

[37] S. Umrao, S. Abraham, F. Theil, S. Pandey, V. Ciobota, P.K. Shukla, C.J. Rupp, S. Chakraborty, R. Ahuja, J. Popp, B. Dietzek, A. Srivastava. A possible mechanism for the emergence of an additional band gap due to a $\mathrm{Ti}-\mathrm{O}-\mathrm{C}$ bond in the $\mathrm{TiO}_{2}-$ graphene hybrid system for enhanced photodegradation of methylene blue under visible light, RSC Adv. 4 (2014) 59890-59901.

[38] S. Campidelli, L. Pérez, J. Rodríguez-López, J. Barberá, F. Langa, R. Deschenaux. Dendritic liquid-crystalline fullerene-ferrocene dyads, Tetrahedron 62 (2006) 2115-2122.

[39] K.M. Reddy, S.V. Manorama, A.R. Reddy. Bandgap studies on anatase titanium dioxide nanoparticles, Mater. Chem. Phys. 78 (2003) 239-245.

[40] Y. Liu, R.O. Claus. Blue light emitting nanosized $\mathrm{TiO}_{2}$ colloids, J. Am. Chem. Soc. 119 (1997) 5273-5274. 
[41] C. Kormann, D.W. Bahnemann, M.R. Hoffmann. Preparation and characterization of quantum-size titanium dioxide, J. Phys. Chem. 92 (1988) 5196-5201.

[42] Y. Guo, L. Chen, Y. Song, P. Hu, S. Chen. Ruthenium nanoparticles stabilized by the selfassembly of acetylene, carboxylate, and thiol derivatives, Sci. Adv. Mater. 6 (2014) 10601067.

[43] D. Pan, N. Zhao, Q. Wang, S. Jiang, X. Ji, L. An. Facile synthesis and characterization of luminescent $\mathrm{TiO}_{2}$ nanocrystals, Adv. Mater. 17 (2005) 1991-1995.

[44] P. Hu, Y. Song, M.D. Rojas-Andrade, S. Chen. Platinum nanoparticles functionalized with ethynylphenylboronic acid derivatives: Selective manipulation of nanoparticle photoluminescence by fluoride ions, Langmuir 30 (2014) 5224-5229.

[45] Y. Song, X. Kang, N.B. Zuckerman, B. Phebus, J.P. Konopelski, S. Chen. Ferrocene functionalized carbon nanoparticles Nanoscale 3 (2011) 1984-1989.

[46] G.-L. Xu, R.J. Crutchley, M.C. DeRosa, Q.-J. Pan, H.-X. Zhang, X. Wang, T. Ren. Strong electronic couplings between ferrocenyl centers mediated by bis-ethynyl/butadiynyl diruthenium bridges, J. Am. Chem. Soc. 127 (2005) 13354-13363. 
Graphic Abstract

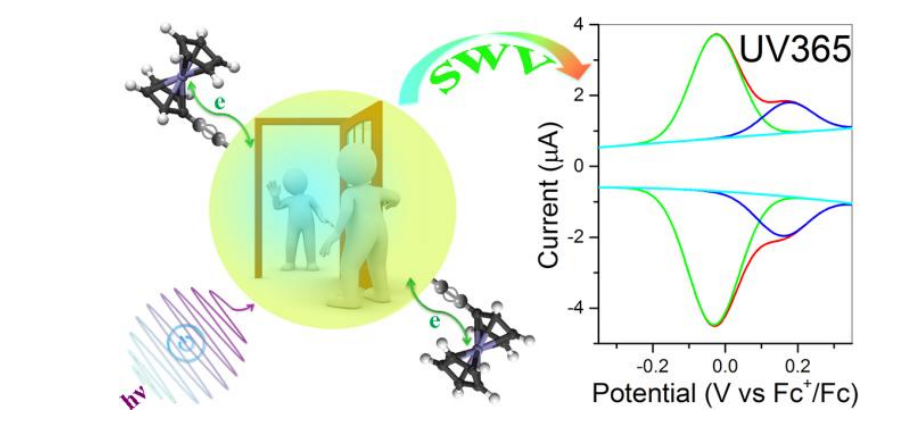

. 